Uşak Üniversitesi Sosyal Bilimler Dergisi

2014, 7(1), 204-216

\title{
İlköğretim Sosyal Bilgiler Öğretmenlerinin Ders İçi Yerel Tarih Konusundaki Faaliyetleri Uşak İli Örneği
}

Özet

\author{
Barış METIN* $*$ \\ Mehmet ORAN**
}

Bu çalışma, Milli Eğitim Bakanlığı'nın Sosyal Bilgiler dersinde yer alan yerel tarih konularının İlköğretim Sosyal Bilgiler öğretmenleri tarafından anlatılıp anlatılmadı̆̆ını bulmak amacıyla yapılmıştır.Araştırmada ilk etapta kısa bir şekilde Sosyal Bilgiler dersinin tanımı ve amacı açıklanmıştır. Daha sonra yerel tarih, yerel tarihin gelişimi, faydaları ve sınırlılıkları, İlköğretim Sosyal Bilgiler dersinde yer alan yerel tarih konuları üzerine yoğunlaşılmıştır. Yerel tarih konularının öğretimi ve işlenişi konusunda İlköğretim Sosyal Bilgiler öğretmenlerinin görüşlerini belirlemek amacıyla yarı yapılandırılmış görüşme formu hazırlanmıştır ve İlköğretim Sosyal Bilgiler öğretmenlerine uygulanmıştır.Araştırma kapsamında Uşak ili merkez ve ilçelerinde görev yapan 123 Sosyal Bilgiler öğretmeninden 15 Sosyal Bilgiler öğretmenine yarı yapılandırılmış mülakat uygulanmıştır. Yerel tarihi konular öğretilirken öğretmenlerin ilgili durumlar üzerindeki görüşlerini tanımlamak için kullanılan bu tür aktiviteler analiz edilip değerlendirilir. Bu bilgiler öğretmenlerin ortaokul seviyesindeki yerel tarihin öğretiminin geçmişin ve şimdinin daha iyi anlaşılması gerektiği düşüncesini gösteriyor. Buna rağmen Sosyal Bilgiler müfredatı yeteri kadar yerel tarihi içermiyor. Bunun yanında araştırmalar gösteriyor ki öğretmenler derlerinde yerel tarihe daha fazla yer vermeye çalışıyor, fakat müfredat, ders saati ve öğretim materyallerindeki eksiklik onların bu amaca ulaşmalarını engelliyor.

Anahtar Kelimeler: Yerel Tarih, Sosyal Bilgiler Dersi, İlköğretim Sosyal Bilgiler Öğretmenleri.

\footnotetext{
*Yrd.Doç.Dr.,Uşak Üniversitesi, Eğitim Fakültesi, İlköğretim Bölümü

** Uşak Üniversitesi, Sosyal Bilimler Enstitüsü, Yüksek Lisans Öğrencisi
} 
Sosyal Bilimler Dergisi 205

\title{
Activities on Local History Carried Out by Teachers in Social Studies Lessons: The Sample of Uşak Province
}

\begin{abstract}
This study has been carried out to determine whether local history topics, placed in Social Science curriculum, is tought by Primary Social Studies teachers or not.In the first phase of this study, the definition and purpose of Social Studies have been dealt with briefly. Thereafter, the study focuses on local history, its development, facilities, restrictions and the local history mentioned in Social Studies. A semi-structured interview form has been prepared to determine the view of the Social Studies teachers with respect to the teaching and performing local history matters.In the scope of this study, from 123 Social Studies teachers to 12 working in the city center and districts of Uşak province have been carried out with semi- tructured interviews. The data obtained through the interviews are analysed and evaluated to define teachers' perspectives on the relevant matters and the type of activities they use or employ while teachin local history topics. The findings reveal that teachers think that a beter understanding of the past and present requires the teaching of local history in middle school level. However, the Social Studies Curriculum does not introduce local history adequately. It is also found out that teachers try to make space for local history in their lessons, but the relavant requlations, class-time and lack of teaching materials prevent them to achieve that goal.
\end{abstract}

Key Words: Local History, Social Sciences Lesson, Primary Social Sciences Teachers.

\section{Giriş}

Öğretmenler, eğitim öğretim etkinliklerini planlarken ve uygularken birtakım yeterliliklere de sahip olmalıdırlar. Öğretmenler derslerini öğrencilerin etkili öğreneceği şekilde düzenlemelidir. Öğretmenler eğitim öğretim faaliyetlerinde kullanacağı strateji, yöntem ve teknikleri çok iyi bilmelidirler ve uygulamada da yeterliliğe sahip olmalıdırlar (Taşkaya ve Bal, 2009: 175). Bir eğitim kurumunda çalışan öğretmenler, gerekli niteliğe, donanıma ve standartlara sahip değillerse, öğretimden beklenen verim sağlanamaz. Dolayısıyla öğretim kurumunun başarısı öğretmenlerin meslek öncesinde nitelikli olarak eğitilmelerine, meslek içinde de kendilerine geliştirmelerine bağlıdır (Taş, 2004: 30). 
$\mathrm{Bu}$ çalışma, İlköğretim Sosyal Bilgiler öğretmenlerinin ders içi faaliyetlerinde yerel tarih konularının kullanımını ortaya koymak amacıyla yapılmıştır.

\section{Sosyal Bilgiler Öğretimi ve Yerel Tarih}

Yerel tarih belirli bir yerde yaşamış veya yaşamakta olan toplumların kökenlerini, gelişimlerini, yaşam biçimlerini, sosyal-kültürel-ekonomik gelişmelerini inceleyen bir alandır (Aslan, 2000: 195). Yerel tarih denilince akla yakın çevre, mahalle, köy, ilçe, il gibi birtakım yaşam alanlarının tarihi aklımıza gelmektedir.

"Yerel tarih dediğimizde, öncelikle sinırları belli bir coğrafi alanı, mekânsal bir sabitliği kastediyoruz; Yerel tarih, tarihin bir fiziğe kavuştuğu bir alan, ama bu, yerelin tanımının sadece bir parçası. Çünkü mekân, tek başına pasif bir cüz; dolayısıyla yerel tarih iki temel cüzün yani insanın ve mekânın bir araya geldiği bir bütünlüğ̈̈ ifade ediyor" (Danacıoğlu, 2012: 6).

İnsanlar yaşadıkları coğrafyayı iyi tanımayı ve bilmeyi, kendi bölgesinde gezinmeyi, yani yaşadığı çevrede yerli turist konumundan çıkıp, çevresine daha duyarlı olmayı amaçlar (İlyasoğlu, 2001: 40). Böylece insanlar çevresindeki insanlarla uyum içinde yaşamayı alışırlar ve kendilerinde ben duygusu yerine biz duygusu yerleşmeye başlar. Yani insanlar toplumsal birey olma yolunda önemli bir adıma atmış olurlar. Toplumsallaşma sonunda da bu bireyler toplum tarafından sevilen ve takdir edilen insanlar kategorisine girerler.

Yerel tarihçilik, öncelikle tarihin merkezine insanları alır. Daha sonra insanların tecrübelerini, bu tecrübelerin tarihini, tarihle ilişkisini irdeler. İnsanların düşüncelerini bir tarih bilgisi olarak görür ve bunun değerlendirilmesinin önemi üzerinde durur (İlyasoğlu, 2001: 38).

"Tarihte yerellik ifadesi kişiden kişiye farkh anlamlar çă̆rıştırmaktadır. En genel ifadesiyle yerel tarih: Bir yörenin tarihinin sahip olduğu "kendine özgü" niteliktedir. Bu yörenin geçmişten günümüze tarihi gelişimi ve bu gelişim sonucu o yörede oluşan tarihi izlerdir. Yörenin tarihi geçmişi ve o geçmişten kalan izler o yörenin, bölgenin yerel tarihini oluşturmaktadır" (Işık, 2008: 291).

Yerel tarihin ne anlama geldiğini ve amacının ne olduğunu öğrendikten sonra yerel tarihin kaynaklarının neler olduğuna biraz değinelim. Kaynaklar, insanların geçmişteki faaliyetlerinden geriye kalan her türlü bulguyu içerir (Göç, 2008: 20). İşte bu bulgular yerel tarih öğretiminin gerçekleştirilmesinde bizlere yardımcı olur. 
Ülkemizde yerel tarih ile ilgilenen insanlar sadece arşivlerdeki belgelere bağlı kalarak araştırma-inceleme yapmakta ve başka kaynakları kullanmamaktadır. Oysa ülkemiz tarihi kaynaklar bakımından oldukça zengindir ve birçok yapı, geçmişimize ışık tutabilir (Danacıoğlu, 2001: 173).

Ülkemiz yerel tarihe kaynak olabilecek birçok unsuru bünyesinde barındırmaktadır. Ancak ülkemizde tarihsel geleneğin geçmişi yukarıda da belirttiğimiz gibi arşivlerde aramaya odaklı olduğu söylenebilir (Avcı Akçalı, 2007: 67). Bu yüzden yerel tarihimizi incelemek istersek daha çok yazılı kaynaklardan yararlanacağımızı belirtmekte fayda vardır.

Yerel tarihin öğretiminde kullanılabilecek kaynakları şu şekilde siralayabiliriz (Douch, 1972; Mays, 1974; Pluckrose, 1995; Griffin ve Lomas, 1997; Akt. Demircioğlu, 2005: 71-72):

- Kitaplar ve Diğer Yazılı Kaynaklar: Genel eserler, yerel bibliyografya ve tarihler, periyodik yayınlar, rehber kitapları, hatıralar, gazeteler ve nutuklar.

- Haritalar: Modern haritalar, tarihsel haritalar, ilçe haritaları ve kırsal kesim haritaları.

- Jeolojik ve Coğrafi Unsurlar: Kayalar, şekiller, kalıntılar, drenajlar, iklim, toprak ve bitkiler.

- İsimler: Soyadları, bina, kasaba, köy, mezra, cadde isimleri.

- Arkeolojik Kalıntılar: Taşınabilir materyaller ve saha kalıntıları.

- Binalar: Bina grupları, bina amblemleri, sinır yapıları, okullar, evler, hanlar ve dini yapilar.

- Arșivler: Basılı yazılımlar, orijinal dokümanlar, arşiv depolarındaki kayıtlar, ailelerin ellerinde bulunan belgeler, ilçelerdeki resmi yazılar ve şirket arşivleri.

- $\quad$ Resim ve Diğer Görseller: Tablolar, portreler, gravürler, fotoğraflar vb.

- Yollar, Kanallar ve Demiryolları: Tarihi yollar, kanallar ve demiryolları.

- Endüstri Kurulușları: Fabrikalar, atölyeler vb.

- Televizyon ve Radyo Programları: Radyo programları, televizyon programları, belgeseller vb.

Bunlara ilave olarak Eyrice (2005:7), salnamelerin de birer yerel tarih kaynağı olduğunu ifade etmektedir. Salnamelerde vilayetlerdeki idareciler, idari yapı, bölgenin coğrafi ve iklim özellikleri, ekonomik faaliyetleri, okulları, kütüphaneler hakkında bilgi vermektedir. 
Yerel tarihin faydalarına değinecek olursak yerel tarih sayesinde öğretmenler öğrencilerin dikkatlerini yaşadığı topluma çekmeye yardımcı olur. Yani yerel tarih, güncel hayatla yaşamı birleştirir. Yerel tarih çalışmalarını okul dışında yürüten öğrenci ise pek çok insanla iletişim kurarak araştırma yapmakta ve hayatını sorgulayabilmektedir (Tunç Şahin, 2011: 455). Ayrıca yerel tarihin faydalarından bir diğeri de dış dünya ile okul arasındaki sınırların aşılmasına yardımı olmasıdır. Öğrencilerin yerel tarih ile ilgili çalışmaları boyunca arşivci, müzeci, yerel tarihçi gibi ilgililerle yapacakları görüşmeler, öğrencilerin çevrelerindeki kültürel ve tarih zenginliklerin farkına varmalarına ve onlarda belki de ömür boyu sürecek bir kültür ve tarih zevkinin oluşmasına yardımcı olacaktır (Aktekin, 2001: 208).

Yerel tarihin sinırlılığına değinecek olursak, yerel tarih öğretimine dayalı etkinliklerin hazırlanmalarının çok zaman almasıdır (Demircioğlu, 2005: 79). Yine aynı şekilde (Tunç Şahin, 2011: 455) belirttiği gibi her geçen gün öğretmenler için uygulamasının zorlaşmasıdır. Ayrıca bir yerel tarihçinin veya yerel tarihi öğretim etkinliklerinde kullanacak olan öğretmenlerin, tarihsel verilerin sınırlılıklarını bilmeleri gerekmektedir (Demircioğlu, 2005: 72).

Yerel tarihe dayalı bir öğretim öncesi öğretmenlerin dikkat etmesi gereken en önemli hususlardan birisi de öğrencilerin hazır bulunuşluk seviyesidir. Hazır bulunuşluk seviyesi, öğrencinin belirli bir konuya giriş seviyesidir ve konuyla ilgili ön bilgi ve tutumunu içerir. İleri düzeyde giriş seviyesine sahip olan öğrenciler için karmaşık, soyut ve çok yönlü etkinlikler düzenlenebilir. İleri düzeyde giriş seviyesine sahip olmayan öğrenciler için ise daha basit ve somut etkinlikler düzenlenmelidir (Yenilmez ve Kakmacı, 2008: 530).

\section{Problem Durumu ve Alt Problemler}

Sosyal Bilgiler öncelikle ulusal ve evrensel değerlerle donanmış, aktif ve iletişime açı demokratik vatandaşlar yetiştirmeyi amaçlar (Kan, 2009: 28). Bu amaçla son yıllarda Sosyal Bilgiler dersi programında köklü değişiklikler yapılmıştır. Yapılan bu değişikliklerle birlikte Sosyal Bilgiler dersinde yerel tarih konuları önem kazanmaya başlamıştır. Bu çalışma, Milli Eğitim Bakanlığı'nın Sosyal Bilgiler dersinde yer alan yerel tarih konularının İlköğretim Sosyal Bilgiler öğretmenleri tarafından nasıl işlendiğini bulmak amacıyla yapılmıştır. Amaç ve problem durumu göz önüne alınarak aşağıdaki sorulara cevap aranmıştır: 
Sosyal Bilimler Dergisi 209

1. İlköğretim Sosyal Bilgiler öğretmenlerinin yerel tarih hakkındaki düşünceleri nelerdir?

2. İlköğretim Sosyal Bilgiler öğretmenlerinin yerel tarihe dair ders içi etkinlikleri nelerdir?

3. İlköğretim Sosyal Bilgiler öğretmenlerinin, yerel tarihin derslerde kullanımına ilişkin görüşleri nelerdir?

4. İlköğretim Sosyal Bilgiler öğretmenlerinin yerel tarih öğretiminde kullanılan ya da kullanılabilecek yöntem ve teknikler hakkındaki görüşleri nelerdir?

$\mathrm{Bu}$ çalışmada, İlköğretim Sosyal Bilgiler öğretmenlerinin yerel tarih hakkındaki duygu ve düşünceleri ile yerel tarihe dair faaliyetleri tespit edilmiştir. Ayrıca İlköğretim Sosyal Bilgiler öğretmenlerinin yerel tarihi öğretirken karşılaştıkları sıkıntıları dile getirmesi açısından bu çalışma önemlidir.

\section{Yöntem}

Bu bölümde araştırmanın modeli, çalışma grubu, veri kaynakları, veri toplama aracı ve verilerin analizi ile ilgili açıklamalar yer almaktadır.

Araştırmada nitel araştırma tekniklerinden durum çalışması modeli uygulanmıştır. Uygulama bölümünde ise Uşak ilinde İlköğretim Sosyal Bilgiler öğretmenlerinin yerel tarihe dair duygu, düşünce ve faaliyetlerini öğrenmek amacıyla açık uçlu sorular sorularak yarı yapılandırılmış mülakat (görüşme) uygulanmiştır.

Araştırmanın çalışma grubunu Uşak ili merkez ve ilçelerinde bulunan, Milli Eğitim Müdürlüğü'ne bağlı ilköğretim okullarında görev yapan Sosyal Bilgiler öğretmenleri oluşturmaktadır.

Araştırma kapsamında Uşak ili merkez ve ilçelerinde görev yapan 123 Sosyal Bilgiler öğretmeninden 15 Sosyal Bilgiler öğretmenine mülakat uygulanmıştır. Araştırmaya katılan 15 Sosyal Bilgiler öğretmenin 4'ü merkez okullarından olup diğer 11 tanesi ilçe okullarında görev yapmaktadır. Araştırmada her ilçeden öğretmene yer verilmiştir ve böylelikle coğrafi temsil sağlanmaya çalışılmıştır. Araştırmada kasıtlı örnekleme tekniği kullanılmıştır. Öncelikle literatür taraması yapılarak sorular hazırlanmış ve uzman görüşüne başvurulmuştur. Uzman görüşü doğrultusunda hazırlanan yarı yapılandırılmış görüşme formu uygulanmıştır. Mülakat esnasında araştırmaya katılan İlköğretim Sosyal Bilgiler öğretmenlerinin mülakat sorularına verdikleri 
cevaplar ses kaydına alınarak Word dosyasına aktarılmıştır. Word dosyasına aktarılan bu cevapların her satırına satır numarası verilmiştir. Daha sonra araştırmaya katılan İlköğretim Sosyal Bilgiler öğretmenlerinin vermiş olduğu cevaplara kodlamalar yapılmıştır ve veriler analiz edilmiştir.

Mülakat sorularına verilen cevaplar, katılımcı sayıları, oranları ve daha önce konu üzerine edinilen bilgiler ışığında betimsel olarak yorumlanmıştır.

Araştırmada öğretmenlere sorulan yerel tarih hakkındaki düşünce ve yerel tarihi kullanımına dönük mülakat sorularına verilen cevaplar incelenmiştir. Verilerin analizi esnasında çalışmanın güvenilirliğini artırmak için 3 alan uzmanına kodlamalar yaptırılmıştır.

Yapılan mülakatların analizi sırasında veriler kodlama yoluyla kategorilere ayrılmıştır. Veriler ilk etapta 39 koda ayrılmıştır, daha sonra bu kodlar kendi aralarında ilişkilendirilerek bu sayı 22'ye düşürülmüştür. Bu kodların bazıları şunlardır: Gerekli, Gezi-Gözlem, Teknolojiyi Kullanma, Düz Anlatım, Sözlü (Hikayeci) Tarih, Soru-Cevap, Ev Ödevi, Araştırma-İnceleme, Proje-Performans, Yakından-Uzağa, Merak, Motivasyon, İlgi, YaparakYaşayarak Öğrenme, Kalıcılık, Kültür, Milli Bilinç, Maddi Sorunlar, Müfredat, İzin, Hazır bulunuşluk, Belge ve Doküman Eksikliği, Kişisel Bilgi Eksikliği

\section{Bulgular ve Yorumlar}

Yerel Tarih hakkında katılımcıların genel görüşleri şöyledir:

Araştırmaya katılan İlköğretim Sosyal Bilgiler öğretmenlerinin hepsi yerel tarih ile ilgili genel görüsslerinde olumlu ifadelerde bulunmuşlardır. Araştırmaya katılan öğretmenlerden bazıları Sosyal Bilgiler dersinde yerel tarih kullanmanın önemini ve gerekliliğini vurgulamışlardır. Ayrıca görüşme yapılan İlköğretim Sosyal Bilgiler öğretmenlerinden bazıları Sosyal Bilgiler müfredatında yeteri kadar yerel tarihin olmadığını da vurgulamıştır. K. 1, “Tarih öğretiminde yerel tarihin yani kendi bulunduğumuz yerin tarihini öğrenmek çok önemli." (st. 5-6) biçiminde görüş bildirmiştir. K. 11 ise, "Öğrencilerimizin yaşadıkları bölgelerimizin tarihini bilmeleri her zaman daha iyidir. Tarihini bilen öğrenci her zaman gelecekle ilgili daha önemli kararlar verebilir." (st. 558-561) biçiminde görüş bildirmiştir.

İlköğretim Sosyal Bilgiler öğretmenleri derslerde yerel tarihe ilişkin bilgilerin kullanımına ilişkin görüşlerinde, katılımcıların çoğu derslerinde yerel tarihi kullandıkları görüşünü savunmuşlardır. K. 7, "Yeri geldiğinde ders kaynaklarımızda bunları belirtiyoruz. Özellikle biz 6. sinıfta Anadolu Medeniyetleri, 7. 
Sosyal Bilimler Dergisi 211

sinıfta Osmanl Imparatorluğu ve Selçuklu'dan bahsederken bu bölgelerden de bahsediyoruz." (st. 396-398) biçiminde görüş bildirmişlerdir. İlköğretim Sosyal Bilgiler öğretmenlerinden bazıları ise derslerinde yerel tarihi kullanamadıklarını savunmuşlardır. Bu öğretmenler müfredat, belge ve doküman eksikliği ve kişisel bilgi eksiklikleri nedeniyle derslerinde yerel tarihi kullanamadıklarını bildirmişlerdir. K. 1, "Tarihi bir olay olmaması tabi yerel tarihte kullanamamamızın bi nedeni. Yani sınırlı." (st. 33-34) biçiminde görüş bildirmişlerdir. K. 6, "Çok sınırl, yani çok az." (st. 355) biçiminde görüş bildirmiştir. K. 8 ise, "Kitaplarda, ders kitaplarında bu konuda bir şey yok." (st. 461) biçiminde görüş bildirmiştir.

İlköğretim Sosyal Bilgiler öğretmenlerinin yerel tarih öğretiminde kullanılabilecek yöntem, teknik ve etkinlikler hakkındaki görüşlerinde, katılımcıların çoğu yerel tarih öğretiminde birtakım yöntem, teknik ve etkinlikleri savunmuşturlar. Görüşme yapılan İlköğretim Sosyal Bilgiler öğretmenlerinin tamamı gezi-gözlemi savunmuştur, Bunu teknoloji kullanma, düz anlatım, sözlü (hikâyeci) tarihi, soru-cevap, ev ödevi-araştırmaproje/performans, yakından uzağa yöntem, teknik ve etkinliklerini takip etmiştir. K. 3, "Tarihi yerlere bizzat gidip, görüp fotoğraflanması ve onu da sinıfa getirirsek, görmemiş olan öğrencilerimiz de görmüş oluyor." (st. 221-222), K. 1, "Konuşarak dedesinden o günün şartların dinleyerek belki bir şeyler öğrenebilir. Yani sözlü tarih çalışması yaparsa faydası olur." (st. 48-49), K. 11, "Tabiki soru-cevap şeklinde yani öğrencilerin ön bilgilerini öğrenmeye yönelik teknikleri kullanıyoruz. Ön bilgilerini ortaya çıkarmak için de soru-cevap tekniğini kullanıyoruz" (st. 567-568), K. 8, "Zaten derslerimizi anlatırken yakından uză̆a doğru, yani kendi köyünü, ilçesini bilirse, diğerlerini daha iyi öğrenir." (st. 478-479) biçimlerinde görüş bildirmişlerdir.

İlköğretim Sosyal Bilgiler öğretmenleri yerel tarihin eğitimde kullanılmasına ilişkin görüşlerinde, araştırmaya katılan İlköğretim Sosyal Bilgiler öğretmenleri öğrencide merakın, motivasyonun, ilginin ve yaparakyaşayarak öğrenmenin artacağını bildirmişlerdir. K. 2, "Dedemizi veya geçmişimizi merak etme olayı vardır. Bir çocuğun yaşadığı bölgenin tarihini o bölge işte kimler tarafindan kurulmuş, kendi ailesi oraya ne zaman gelmiş bunlar çok önemli ve merak edilen şeyler." (st. 147-150) biçiminde görüş bildirmiştir. K. 5, "Öğrencilerin yaşadığı yerin tarihi içerisindeki önemini bilmesi tarih öğrenme konusunda onu daha hevesli hale getirebilir." (st. 115-116) biçiminde görüş bildirmiştir. K. 11, "Öğrencilerin bildiğiyse derse daha çok motive eder." (st. 578-580) biçiminde görüş bildirmiştir." (st. 578-580) biçiminde görüş bildirmiştir. K. 3 ise, "Öğrencilerin 
yakın çeoresi daha çok ilgi çektiği için yerel tarih daha çok ilgi çekmektedir." (st. 226228) biçiminde görüş bildirmiştir

İlköğretim Sosyal Bilgiler öğretmenleri yerel tarih bilgilerinin kullanılmasının öğrenciye sağlayacağı yararlar hakkında görüş bildirmişlerdir. Katılımcılar, İlköğretim Sosyal Bilgiler öğretmenleri yerel tarihin derslerde kullanılmasının öğrencide kalıcılık bakımından, kültür bakımından, bağlantı kurma bakımından ve milli bilinç bakımından yararlar sağlayacağını düşünmektedirler. K. 6, "Kalıcı olur, evet kalıcı olur." (st. 372-375) biçiminde görüş bildirmiştir. K. 3, "Öğrenci önce kendi çevresini bilmesi lazım, nerede yaşadığını bilmesi lazım, kendi çevresini öğrenerek daha geniş bir bilgiye sahip olabilir." (st. 223225) biçiminde görüş bildirmiştir. K. 10 ise, "Çocuklar öncelikle kendi yaşadıkları şeyleri ve kendi görüşlerini öğrenirlerse, tarihle ilgili konuları daha iyi anlayabileceklerini düşünüyoruz." (st. 538-540) biçiminde görüş bildirmiştir. K. 13 ise, "Öğrencilere verilen bilgiler sayesinde, kendi kentlerini sahip çıkacaklarını, kendi tarihi değerlerine sahip çıkacaklarını, oyunların yemeklerini, giysilerini, kültürlerini unutmayıp gelecek kuşaklara aktaracaklarını düşünüyorum yani." (st. 668-671) biçiminde görüş bildirmiştir.

İlköğretim Sosyal Bilgiler öğretmenleri yerel tarih ile ilgili karşılaştıkları sorunları dile getirmişlerdir. Araştırmaya katılanların çoğunluğu yerel tarih ile ilgili bilgileri derslerde kullanırken maddi sorunlar bakımından, müfredat bakımından, izin bakımından, hazır bulunuşluk bakımından, belge ve doküman eksikliği bakımından ve kişisel bilgi eksikliği bakımından sorunlar yaşadığını bildirmişlerdir. K. 6, "Yerel tarih araştırmalarıyla ilgili en önemli karşılaştığımız sorun maddi sorunlar bence." (st. 376-379) biçiminde görüş bildirmiştir. K. 2, "Müfredatta çok fazla yerel tarihe değinilmiyor." (st. 85-90) biçiminde görüş bildirmiştir. K. 7, "Özellikle resmi prosedürle ilgili bir sıkıntı yaşıyoruz." (st. 446-448) biçiminde görüş bildirmiştir. K. 3, "Öğrenciler arkeoloji müzesine gittiği zaman çok eski tarihle günümüz tarihi arasında bağlantı kurmakta zorluk çekiyorlar." (st. 237-238) biçiminde görüş bildirmişlerdir. K. 2, "Tarih öğretmenlerinin elinde bir doküman olması lazım. Yani daha önceden araştırılması lazım. Yani dilinde olan sonradan uydurma şekilde veya halkın türetmesiyle oluşmuş bilgilerle de bu tarih verilemez." (st. 130-135) biçiminde görüş bildirmiştir. K. 5, "Tarihi yerler hakkında bilgiler bizim de eksik. Bizim de bilgilerimiz eksik olduğu için öğrencilere bunu anlatmakta birtakım sorunlar yaşıyoruz." (st. 338-339) biçiminde görüş bildirmiştir. 
Sosyal Bilimler Dergisi 213

\section{Sonuç, Tartışma ve Öneriler}

Değişen ve gelişen Sosyal Bilgiler dersi müfredatıyla öğrenciler artık araştırıcı ve sorgulayıcı bir nitelik kazanmışlardır. Sosyal Bilgiler öğretmenleri ise geleneksel ders işleme metotlarını terk ederek, öğrencilerin derste daha aktif bir rol oynamalarına olanak sağlamışlardır. Böylece öğretmenlerin değil de, öğrenci ve etkinliklerin merkezde olduğu bir anlayış oluşmuştur.

Araştırma ile yerel tarihin ne olduğu, amaçlarının neler olduğu, Sosyal Bilgiler müfredatında ne kadar yer aldığını, faydalarının ve sınırlılıklarının neler olduğu, kaynaklarının neler olduğu belirtilmiştir. Ayrıca bu çalışma ile İlköğretim Sosyal Bilgiler öğretmenlerinin yerel tarih hakkındaki düşünce ve görüşleri, derslerde yerel tarihe ilişkin bilgileri kullanıp kullanmaması, kullanıyor iseler hangi yöntem-teknik-etkinlikleri kullandıkları, yerel tarihin eğitimde kullanılmasına dair görüşleri, öğrenciye sağlayacağı yararlar hakkındaki düşünceleri ve son olarak da yerel tarih ile ilgili bilgileri derslerde kullanırken herhangi bir sorun ile karşılaşılması hakkındaki düşünce ve görüşleri ortaya konmuştur.

İlköğretim Sosyal Bilgiler öğretmenlerine yöneltilen "Yerel tarih hakkındaki düşünce ve görüşleriniz nelerdir?" sorusuna araştırmaya katılan öğretmenlerin çoğu yerel tarihin önemli ve gerekli olduğunu belirtmiştir. Fakat araştırmaya katılan bazı öğretmenler ise Sosyal Bilgiler müfredatında yerel tarihin yeteri kadar yer bulmadığını da dile getirmişlerdir.

"Derslerinizde yerel tarihi kullanıyor musunuz?" sorusuna araştırmaya katılan öğretmenlerinin çoğu kullandıklarını belirtmişlerdir. Ancak az da olsa birkaç öğretmen derslerinde yerel tarihi kullanamadıklarını dile getirmiştir. Bunların nedenleri ise müfredat, belge ve doküman eksikliği ile öğretmenlerin yeteri kadar yerel tarih hakkında bilgi sahibi olmamaları olarak tespit edilmiştir.

İlköğretim Sosyal Bilgiler öğretmenlerine yöneltilen "Yerel tarih öğretiminde kullanılabilecek yöntem, teknik ve etkinlikler hakkındaki görüşleriniz nelerdir?" sorusuna araştırmaya katılan öğretmenlerin hepsi birçok yöntem, teknik ve etkinlikler söylemişlerdir. Genel itibariyle en fazla gezigözlem tekniği söylenmiştir. Bunu sırasıyla teknolojiyi kullanma, yakındanuzağa, sözlü (hikâyeci) tarih, ev ödevi/araştırma-inceleme/proje-performans takip etmiştir. En az söylenenler ise düz anlatım ve soru-cevaptır.

"Yerel tarihin eğitimde kullanılmasına ilişkin görüşleriniz nelerdir?" sorusuna araştırmaya katılan öğretmenlerden bazıları öğrencide merak, motivasyon ve ilginin artacağı yönünde görüş bildirmişlerdir. 
İlköğretim Sosyal Bilgiler öğretmenlerine yöneltilen "Yerel tarih bilgilerinin kullanılmasının öğrenciye sağlayacağı yararlar hakkında ne düşünüyorsunuz?" sorusuna araştırmaya katılan öğretmenler çeşitli görüşler bildirmişlerdir. Bunlar öğrencide kalıcı bilgiyi sağlama, öğrencide kültür oluşturma ve öğrencide milli bilinci güçlendirme şeklinde dile getirilmiştir.

"Yerel tarih ile ilgili bilgileri derslerde kullanırken herhangi bir sorun ile karşılaşıyor musunuz?" sorusuna araştırmaya katılan öğretmenler farklı birçok sorunu dile getirmişlerdir. Genel itibariyle en fazla öğretmenler müfredattan yakınmışlardır. Bunu sırasıyla maddi sorunlar, izin, belge ve doküman eksikliği takip etmiştir. En az dile getirilenler ise öğretmen bilgi eksiklikleri ve öğrencilerinin hazır bulunuşluklarıdır.

Bu bulgular 1şı̆̆ında şu önerilerde bulunulabilir:

1. Öncelikle yerel tarih konuları Sosyal Bilgiler dersi içerisinde daha fazla yer verilebilir ve derslerde işlenen konuların öğrencilerin zihinlerinde somutlaşmasını sağlayacak geziler düzenlenerek konuların kalıcılığı sağlanabilir.

2. Öğrenciler yakın tarihe daha fazla ilgi duydukları için, yaşadıkları ilçe, köy, mahalle, bir yapı veya mekânları araştırıp inceleyebilir, sözlü (hikâyeci) tarih yöntemini kullanarak da bilgiler edinebilirler ve derslerde görselliğin kullanılması öğrenmeyi kolaylaştıracağından teknolojik imkânlardan daha çok yararlanılıp öğrenciler müzelere götürülebilir.

3. Yerel tarih için gezi planlaması yapılırken Milli Eğitim Müdürlügü̈nden çıkacak iznin daha hızlı yürütülmesi sağlanabilir.

4. İlköğretim Sosyal Bilgiler öğretmenlerine yerel tarih konusunda ve bu konuda ne tür aktivitelerin yapılabileceklerini göstermeye yönelik uzman kişiler tarafından hizmet içi eğitim ve seminerler verilebilir. 
Sosyal Bilimler Dergisi 215

\section{Kaynakça}

Aktekin, S. (2001), Bulunduğu Eser: Yerel Tarihçilik, Kent, Sivil Girişim Yerel Tarih Grupları Deneyimi, (Ed. Çelebi, F.), İstanbul: Türkiye Ekonomik ve Toplumsal Tarih Vakfı, 186-213.

Aslan, E. (2000). Yerel Tarihin Tanımı, Gelişimi ve Değeri, Tarih Yazımında Yeni Yaklaşımlar: Küreselleşme ve Yerelleşme, Türkiye Ekonomik ve Toplumsal Tarih Vakfı, İstanbul.

Avcı Akçalı, A. (2007), "Yerel Tarih ve Tarih Ĕ̆itimine Katkısı", Yayınlanmamış Yüksek Lisans Tezi, Dokuz Eylül Üniversitesi Eğitim Bilimleri Enstitüsü Tarih Eğitimi Ana Bilim Dalı Tarih Öğretmenliği Programı, İzmir.

Danacıoğlu, E. (2001), Yerel Tarih Çalışmalarında Kaynak Kullanımı, Bulunduğu Eser: Yerel Tarihçilik, Kent, Sivil Girişim Yerel Tarih Grupları Deneyimi, (Ed. Çelebi, F.), İstanbul: Türkiye Ekonomik ve Toplumsal Tarih Vakf1, 172-179.

Danacıoğlu, E. (2012), Geçmişin İzleri, Yanı Başımızdaki Tarih İçin Bir Klavuz, Tarih Vakfı Yurt Yayınları, İstanbul.

Demircioğlu, İ. H. (2005), "Tarih Öğretiminde Öğrenci Merkezli Yaklaşımlar", Anı Yayıncilik, Ankara.

Eyrice, N. (2005), Tarih Eğitiminde Yerellik: 1922-1950 Döneminde Menemen Kazası, Yayınlanmamış Yüksek Lisans Tezi, Dokuz Eylül Üniversitesi Eğitim Bilimleri Enstitüsü, İzmir.

Göç, N. (2008), Yerel Tarih Konularının Sosyal Bilgiler Dersinde Uygulanması: Karşılaşılan Güçlükler ve Çözüm Önerileri, Yayınlanmamış Yüksek Lisans Tezi, Gaziosmanpaşa Üniversitesi Sosyal Bilimler Enstitüsü, Tokat.

Işık, H. (2008), “ilköğretimde Tarih Konularının Yerel Tarih İle İlişkilendirilmesinin Öğrenci Başarısına Etkisi", Ankara: Uluslararası Sosyal Araştırma Dergisi.

İsyasoğlu, A. (2001), Yerel Tarih Gruplarıyla Tanışırken: Konular, Sorular, Bulunduğu Eser: Yerel Tarihçilik, Kent, Sivil Girişim Yerel Tarih Grupları 
B.METIN, M. ORAN | 216

Deneyimi, (Ed. Çelebi, F.), İstanbul: Türkiye Ekonomik ve Toplumsal Tarih Vakf1, 37-42.

Kan, Ç. (2009), "Sosyal Bilgiler Eğitiminde Küresel Vatandaşlık", Pamukkale Üniversitesi Ĕ̆itim Fakültesi Dergisi, (26,) 25-30.

Metin Taş, A. (2004) "Sosyal Bilgiler Öğretmenliği Eğitimi Program Standartlarının Belirlenmesi", Ankara Üniversitesi Eğitim Bilimleri Fakültesi Dergisi, 37, (1), 28-54.

Taşkaya, S. M. ve Bal, T. (2009), "Sınıf Öğretmenlerinin Sosyal Bilgiler Öğretim Yöntemlerine İlişkin Görüşleri", Selçuk Üniversitesi Ahmet Keleşoğlu Eğitim Fakültesi Dergisi, (27), 173-185.

Tunç Şahin, C. (2011), "Yerel Tarih Uygulamalarının Başarıya ve Öğrenci Ürünlerine Etkisi", Uluslararası Sosyal Araştırma Dergisi, (16), 453-462.

Yenilmez, K. ve Kakmacı, Ö. (2008), “İlköğretim Yedinci Sınıf Öğrencilerinin Matematikteki Hazır bulunuşluk Düzeyi”, Kastamonu Eğitim Dergisi, 16, (2), 529-542. 